\title{
Participation in real-world laboratories in a new light?! Closing the gap between co-creative and deliberative participation
}

\author{
Marco Sonnberger, Doris Lindner \\ Received: 26 August 2020 - Accepted: 28 June 2021 - Published online: 16 July 2021
}

\begin{abstract}
Sustainability-oriented real-world laboratories involve the co-design and co-creation of knowledge, based on a transdisciplinary cooperation between actors from different social worlds - academia, the administration, business, civil society each endowed with specific interests, resources and worldviews. Sustainability-oriented real-world laboratories claim to be a means of inclusive participation in the co-creative shaping of solutions for socioecological issues and exploring pathways to sustainability. In the literature dealing with sustainability-oriented real-world laboratories, participation is thus mainly understood as active involvement by civil society, change agents and citizens in processes of experimentation and the implementation of solutions. We call this co-creative participation. However, participation in talk-based opinion formation and decision-making processes - we call this deliberative participation - is hardly discussed in the respective literature. In this paper, we argue that co-creative and deliberative participation are two forms of participation which can be conceptualized differently but which are both relevant for
\end{abstract}

Dr. Marco Sonnberger, Zentrum für interdisziplinäre Risikound Innovationsforschung, Universität Stuttgart, Seidenstraße 36, 70174 Stuttgart, Germany marco.sonnberger@zirius.uni-stuttgart.de

Doris Lindner, Zentrum für interdisziplinäre Risikound Innovationsforschung, Universität Stuttgart, Seidenstraße 36, 70174 Stuttgart, Germany doris.lindner@zirius.uni-stuttgart.de

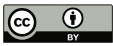
(c) 2021 Lindner; licensee oekom verlag. This Open Access article is published under a Creative Commons Attribution 4.0 International License. successful experimentation in sustainability-oriented realworld laboratories and are mainly intertwined in practice. We propose an ideal-typical conceptual framework for participation in sustainability-oriented real-world laboratories that combines co-creative and deliberative participation. The aim is to contribute to a systematization of, and rationale for, different forms of participation in real-world laboratories.

Keywords: Real-world laboratory = Co-creation Participation - Deliberation - Real-world experiments * Sustainability

Partizipation in Reallaboren in neuem Licht?! Ein Ansatz, die Lücke zwischen ko-kreativer und deliberativer Partizipation zu schließen

\section{Zusammenfassung}

Nachhaltigkeitsorientierte Reallabore beinhalten Ko-Design und Ko-Kreation von Wissen, basierend auf einer transdisziplinären Zusammenarbeit von Akteuren aus verschiedenen sozialen Welten - Wissenschaft, Verwaltung, Wirtschaft, Zivilgesellschaft - jeweils ausgestattet mit spezifischen Interessen, Ressourcen und Weltanschauungen. Nachhaltigkeitsorientierte Reallabore sollen ein Mittel zur inklusiven Partizipation an der ko-kreativen Lösungsfindung für sozialökologische Probleme sein. In der aktuellen Literatur zu nachhaltigkeitsorientierten Reallaboren wird Partizipation zumeist als aktive Beteiligung von Zivilgesellschaft, Pionieren des Wandels und Bürgern in realweltlichen Prozessen des Experimentierens und der Implementation von Problemlösungen verstanden. Wir bezeichnen dies als ko-kreative Partizipation. Formen dialogbasierter Meinungsbildung und Entscheidungsfindung (deliberative Partizipation) finden in der einschlägigen Literatur 
dagegen kaum Beachtung. In diesem Beitrag argumentieren wir, dass ko-kreative und deliberative Partizipation zwei unterschiedlich verfasste Formen von Partizipation sind, die jedoch beide von Relevanz für den Erfolg eines nachhaltigkeitsorientierten Reallabors sind. Wir schlagen einen idealtypischen konzeptionellen Rahmen vor, der ko-kreative und deliberative Partizipationsformen kombiniert und so eine Systematisierung und Begründung unterschiedlicher Partizipationsformen in Reallaboren liefert.

Schlüsselwörter: Reallabore - Ko-Kreation - Partizipation Deliberation - Realexperimente - Nachhaltigkeit

\section{Introduction}

Wicked problems (Rittel/Webber 1973) such as environmental degradation and anthropogenic climate change, which are, inter alia, characterized by ambiguity, complexity and deep uncertainty, call for a form of knowledge production which goes beyond pure disciplinary research (Brown/Harris/Russell 2010; Pohl/Truffer/Hirsch Hadorn 2017). The complexity of wicked problems requires an interdisciplinary perspective for developing a comprehensive understanding of the problem genesis and persistence. Additionally, the ambiguity of problem definitions, and thus the exploration of potential solutions, cannot be adequately handled by academia alone. Due to diverging problem framings among social groups, deliberation about goals and values is necessary in order to build common ground for the exploration of potential solutions. This requires the involvement of all relevant societal actors in different stages of the research process (Renn 2008; Jahn/Bergmann/Keil 2012). This form of problem-oriented research is mainly referred to as transdisciplinary research (Jahn/Bergmann/ Keil 2012).

In the German context, this transdisciplinary approach of doing research on real-world problems has been sharpened by Uwe Schneidewind and others who call for a transformative mode of research which encompasses participatory experimentation with and exploration of potential solutions for pressing socioecological problems in so-called real-world laboratories (Schneidewind/Singer-Brodowski 2013). Subsequently, as part of a broader 'experimental turn' in sustainability science, real-world laboratories as an approach for undertaking problem-oriented research focused on promoting sustainability, have gained widespread attention in Germany and beyond over the last couple of years (Schäpke/
Bergmann/Stelzer et al. 2018: 8). ${ }^{1}$ From a sustainability perspective, a real-world laboratory can be "understood as a targeted set-up of a research 'infrastructure' or a 'space' in which scientific actors and actors from civil society cooperate in the joint production of knowledge in order to support a more sustainable development of society" (Schneidewind/ Augenstein/Stelzer et al. 2018: 12). ${ }^{2}$ Thus, sustainabilityoriented real-world laboratories are considered a means of exploring and learning about different sustainability pathways for sociotechnical systems such as the energy, food or mobility system.

As elaborated by Schäpke, Stelzer, Caniglia et al. (2018), there are five key features of sustainability-oriented realworld laboratories that are frequently mentioned in the respective literature: (a) contribution to transformation ${ }^{3}$, (b) experiments as a core research method, (c) transdisciplinarity as a core research mode, (d) long-term orientation, scalability and transferability of results and (e) learning and reflexivity. Furthermore, co-design and co-production are the two main participatory principles of real-world laboratories. Co-design refers to the involvement of all relevant academic and non-academic actors in the definition of the research problem, the identification of respective research questions and the development of the research design. Thus, co-design involves the inclusive and participatory establishment of a real-world laboratory from the acquisition of research funds to the preparation of the actual research process. Coproduction, in turn, refers to the involvement of relevant academic disciplines as well as relevant non-academic actors in the actual research process - i.e., in the production of new knowledge (Mauser/Klepper/Rice et al. 2013).

These notions of co-design and co-production are rooted in longstanding traditions of participatory design - often also referred to as co-design (Sanders/Stappers 2008: 7) - and participatory action research (Kemmis/McTaggart 2005). In any case, the participation and cooperation of actors from different societal sub-systems is a vital element of real-world laboratories. This is also highlighted by research

\footnotetext{
1 However, while we refer to a sustainability-oriented understanding of real-world laboratories in this paper, there are many other conceptions of laboratories in real-world settings that do not encompass normative commitments to sustainability (Schäpke/ Stelzer/Caniglia et al. 2018: 94; McCrory/Schäpke/Holmén et al. 2020).

2 A similar definition can be found in WBGU (2016: 512).

3 In this context, the term transformation refers "to fundamental shifts in human and environmental interactions and feedbacks" (Hölscher/Wittmayer/Loorbach 2018: 1), which encompass structural changes in culture, values, technologies, modes of production and consumption, infrastructures and policies (Grießhammer/Brohmann 2015: 6).
} 
that has accompanied 14 real-world laboratories in the state of Baden-Wuerttemberg (Germany): "Experience from our accompanying research shows that RwLs can be both, an attempt to implement existing knowledge in a highly participative manner or a transdisciplinary research setting deeply anchored in the field of social action and closely cooperating with its actors to create new knowledge" (Bergmann/ Schäpke/Marg et al. 2021: 560).

However, it is by no means self-evident how participation in real-world laboratories can be structured and implemented in a fair, productive and effective way to ensure that the outcomes of a real-world laboratory meet the legitimacy expectations of citizens and stakeholders. Here, longstanding and unresolved questions concerning the legitimacy and inclusiveness of participation processes gain relevance (Rowe/Frewer 2000; Alcántara/Bach/Kuhn et al. 2016; Vetter/Remer-Bollow 2017). Thus, this paper starts from the research question: How can inclusive participation with legitimate outcomes be generated in the context of sustainability-oriented real-world laboratories? Answers to this question are crucial, since real-world laboratories are contested and pluralistic settings where multiple problem framings and perspectives meet and sometimes also conflict (Engels/Walz 2018; McCrory/Schäpke/Holmén et al. 2020). Furthermore, if the outputs of real-world laboratories are supposed to be scaled-up and/or perpetuated, then the process of output generation needs to be robust in terms of the legitimacy expectations of different social groups, in order to ensure societal acceptability of outcomes.

In this context, the line of argumentation adopted in this paper is as follows. Since participation is a vital element of real-world laboratories, the initiators of real-world laboratories must pay close attention to the design of participation, its strengths and pitfalls. We argue that, in order to - as far as possible - reflexively deal with and potentially circumnavigate potential pitfalls of participation, it is worthwhile to consider the well-established body of research on deliberative participation, which is particularly concerned with the legitimacy of participation processes and outcomes. In our opinion, this has been somewhat neglected in the debate on participation in sustainability-oriented real-world laboratories. These laboratories are by definition not isolated or detached from society but rather have (unintended) real-world consequences on the lifeworlds of citizens and also on political or planning agendas. Thus, participation processes in real-world laboratories, which are oriented towards practical experimentation and ultimately the co-creation of solutions and innovations, could benefit from the incorporation of deliberative forms of participation, which may enhance the legitimacy of the respective solutions and innovations.
Based on our practical experiences in the 'Real-world Laboratory for Sustainable Mobility Culture' ${ }^{4}$ (in the following abbreviated as RNM), we propose a conceptual framework for participation in sustainability-oriented real-world laboratories that pays equal attention to deliberative and co-creative elements of participation and offers a systemic perspective on participation in real-world laboratories. We thereby hope to contribute to a more nuanced understanding of legitimacy issues in real-world laboratories and to identify an avenue for addressing such issues.

In the following, we start with a brief overview of the participation processes in the RNM (Section 2). Then, we turn to the literature on co-creation (Section 3) and deliberation (Section 4) in order to develop a deeper understanding of these two forms of participation. After this, we present and discuss our proposal of a conceptual framework for cocreative and deliberative participation in real-world laboratories (Section 5) and end with a summarizing conclusion (Section 6).

\section{Implications for participation derived from the case of the Real- world Laboratory for Sustainable Mobility Culture}

In 2013, the Ministry of Science, Research and Art of the state of Baden-Württemberg ${ }^{5}$ announced the first funding for real-world laboratories in Germany, with the aim of promoting and developing this new research format and the overarching goal of developing a culture of sustainability in all fields of society (Wagner/Miller 2018: 5). The RNM was funded in a first phase for three years and received additional funding from the German Environment Agency. ${ }^{6}$ In addition to the interdisciplinary project partners of the University of Stuttgart ${ }^{7}$, various cooperation partners from the City of Stuttgart, cultural institutions and civil society

\footnotetext{
${ }^{4}$ Reallabor für nachhaltige Mobilitätskultur, see http://www.r-nm.net/ (11.06.2021).

${ }^{5}$ Ministerium für Wissenschaft, Forschung und Kunst Baden-Württemberg.

6 Umweltbundesamt.

7 Participating institutes were the Institute of Landscape Planning and Ecology (ILPÖ), Institute of Urban Planning and Design (SI), Chair for Transport Planning and Traffic Engineering (ISV), Institute of Sports Science and Kinesiology (INSPO), Institute of Human Factors and Technology Management IAT (IAT), Center for Interdisciplinary Risk and Innovation Studies (ZIRIUS) and International Centre for Cultural and Technological Research (IZKT).
} 


\begin{tabular}{|c|c|c|c|c|c|c|}
\hline project phase & \multicolumn{3}{|c|}{ identification \& ideation } & preparation of & experimentation & evaluation \\
\hline $\begin{array}{l}\text { participation } \\
\text { format }\end{array}$ & $\begin{array}{l}\text { stakeholder } \\
\text { workshop }\end{array}$ & $\begin{array}{l}\text { market of } \\
\text { ideas }\end{array}$ & idea contest & design workshops & $\begin{array}{l}\text { real-world } \\
\text { experiments }\end{array}$ & $\begin{array}{l}\text { reflection work- } \\
\text { shops \& events }\end{array}$ \\
\hline $\begin{array}{c}\text { project \& } \\
\text { participation } \\
\text { objectives }\end{array}$ & $\begin{array}{l}\text { definition of } \\
\text { project goals } \\
\text { \& problem } \\
\text { framings }\end{array}$ & $\begin{array}{c}\text { idea } \\
\text { generation \& } \\
\text { building } \\
\text { cooperations }\end{array}$ & $\begin{array}{l}\text { selection of } \\
\text { real-world } \\
\text { experiments } \\
\text { by jury }\end{array}$ & $\begin{array}{l}\text { planning \& refining } \\
\text { real-world } \\
\text { experiments }\end{array}$ & $\begin{array}{l}\text { actual } \\
\text { implementation of } \\
\text { experiments }\end{array}$ & $\begin{array}{l}\text { analysing \& } \\
\text { reflecting results, } \\
\text { methods, } \\
\text { procedures }\end{array}$ \\
\hline
\end{tabular}

Figure 1 Overview of participation processes in the RNM

initiatives were also involved in the RNM. After the initial phase of three years, the Ministry of Science, Research and Art granted a follow-up funding phase of two more years until August 2020.

The RNM was intended to experiment with sustainable sociotechnical innovations addressing the sociocultural dimension of urban mobility. This was done using a participatory approach involving researchers, students, civil society initiatives, municipal officials, citizens and so-called change agents $^{8}$ (i.e., individuals or organizations that question the status quo and actively promote change; Kristof 2017).

In the first funding phase, four real-world experiments were conducted, and three more in the second. The realworld experiments were - following the real-world laboratory approach as illustrated in the introductory section the core activities of the whole project set-up. Among these real-world experiments was the implementation of a cargo bike system, a rickshaw service for elderly people and the installation of eleven parklets ${ }^{9}$ in the centre of Stuttgart. ${ }^{10}$

Following a participatory approach, non-academic actors were involved in all stages of the project (see Figure 1). In a first step, a stakeholder workshop was conducted in order to discuss and refine the project goals with a broad range of stakeholders (representatives of the municipality of Stuttgart, citizen initiatives dealing with mobility issues, companies providing mobility services etc.), who had not yet been involved as cooperation partners in the application phase of the project. Then, a so-called 'market of ideas'

\footnotetext{
8 The change agents involved in the project were different initiators and spokespersons of local initiatives addressing socioecological issues of mobility in Stuttgart by experimenting with potential solutions. Among these change agents were, for example, the initiators of a citizen cargo bike initiative.

${ }_{9}$ A parklet is a kind of construction or installation on a parking space that transforms the parking space into a public space with sitting accommodation or the like.

10 For a comprehensive illustration and overview of the four realworld experiments conducted during the first funding phase see Reallabor für nachhaltige Mobilitätskultur/Universität Stuttgart (2018).
}

was organized where everybody was invited to pitch and discuss ideas for potential real-world experiments in the RNM. Also, a wide range of heterogeneous actors from the field of urban mobility were invited as additional discussion partners and commentators. A theatre in Stuttgart served as a location for the 'market of ideas'. At the 'market of ideas', around 20 ideas for real-world experiments were presented and discussed. All the attendees then voted to select ten of the ideas for further elaboration. These ideas were subsequently refined by their originators (partly also in teams that had been spontaneously formed at the 'market of ideas') and presented to a jury composed of different representatives of academia, civil society and the administration at an 'idea contest'. The jury finally chose four of the ideas. In the subsequent project phase, the winning teams started to implement their ideas supported by the RNM project team.

The implementation phase was accompanied by several design workshops, which were open to all interested actors and where the actual set-up of the real-world experiments was planned and refined. In a final step, the four real-world experiments were systematically evaluated by the project team and also presented and discussed in reflection workshops and at public events. These public events were particularly necessary since some real-world experiments, like the parklet installations (see Lazarova/Helfenstein/Dietz et al. 2018), had gained widespread public attention and sparked heated public debates in online fora and local newspapers.

As this brief overview of the participatory approach of the RNM shows, different kinds of participation methods have been conducted with varying degrees of success. This has led to reflections within the project team about the limitations of the applied participatory approach. These reflections were systematized in so-called reflection workshops involving the members of the project team and non-academic actors involved in the RNM. In these reflection workshops, two crucial points were brought up: (a) the need for more inclusive involvement of the non-academic actors who were part of the RNM in decisions about the implementation of the different real-world experiments, and (b) the issue of individual citizens and social groups not involved in the RNM 
publicly contesting the legitimacy of some of the real-world experiments.

With respect to the latter point, the RNM has shown that experimentation in public spaces inevitably raises questions of legitimacy, which are likely to be brought up by actors who perceive themselves as being affected by the experiments in question. Since real-world laboratories are by definition spatially situated and also impact this space through their experimental character, people can hardly evade them and are inevitably affected by them.

Going beyond the idea of space as a container and drawing on more complex, relational conceptions of space where space is understood as being enacted and embodied in institutions and thus pre-structuring actions (Löw 2016: xiv), it becomes obvious that this affectedness can take multifaceted and complex forms. Von Wirth and Levin-Keitel (2020), for example, have recently elaborated a typology of space-related impacts of real-world experiments. People affected by the real-world experiments are likely to hold heterogeneous worldviews, values and interests which may also differ from those held by the actors directly involved in the real-world laboratory. Thus, in order to scale and transfer the outcomes of real-world experiments, it becomes crucial to acknowledge, balance and integrate these heterogeneous perspectives in the design, implementation and evaluation of the real-world experiments. This, however, is a complex endeavour which requires a thorough understanding of different shades of participation.

From the two aforementioned points, we have derived the following conclusions with regard to improving participation in real-world laboratory settings. First, since per definition real-world laboratories operate in the lifeworld of individuals, it is vital for securing social acceptability that these individuals perceive experimentation processes and their respective outcomes to be legitimate. Second, since the involvement of non-academic actors in experimentation processes is a central feature of real-world laboratories, close attention has to be paid to the way such actors are allowed to participate in decision-making processes concerning the implementation of real-world experiments, in order to support a sense of fairness.

These conclusions illustrate the need to gain a deeper conceptual understanding of the facets of participation in real-world laboratories. We thus engage with two different strands of research on participation in the following: cocreative and deliberative participation. In the following, we briefly sketch the state of research concerning co-creative participation, since the idea of co-creation is at the core of the real-world laboratory. Then, we turn to the concept of deliberation, since deliberation is regarded as a more fruitful approach for establishing legitimacy in participation processes.

\section{Co-creative participation and issues of legitimacy}

Opening up research to allow non-academic actors to contribute to research design and process, the drawing of conclusions and offering of recommendations involves a cocreative approach to knowledge production. Co-creation as an approach for developing and implementing solutions to real-world problems has gained widespread attention in the last decade, from academia, policymakers and civil society organizations (Voorberg/Bekkers/Tummers 2015). It is expected that co-creation can at least help to address the so-called usability gap between science and policy. In this way, academic knowledge production should be provided with a comprehensive societal basis to balance the power researchers have in defining and analysing the complex societal challenges often associated with issues of sustainability (Frantzeskaki/Rok 2018: 49).

In the broadest sense, co-creation describes the inclusion of diverse knowledge stocks held by different actors in order to find and implement solutions to complex realworld problems (Lund 2018: 3; Frantzeskaki/Kabisch 2016: 91). In the following, we use the term co-creation to denote such processes of joint experimental problem-solving as represented by real-world experiments in real-world laboratories. In a more specific way, co-creation can be understood as a process "to solve a shared problem, challenge, or task through a constructive exchange of different kinds of knowledge, resources, competences, and ideas that enhance the production of public value in terms of visions, plans, policies, strategies, regulatory frameworks, or services" (Torfing/Sørensen/Røiseland 2019: 802).

Processes of co-creation can be set up in a formal or informal way (Puerari/Koning/von Wirth et al. 2018). Formal processes often entail the deliberate selection of participants such as change agents or lead users. In informal processes, in contrast, everyone is considered as a valuable contributor and, thus, informal processes are more open to inclusive participation. However, both formal and informal processes are exposed to the risk of selection bias. While in the case of formal processes, a selection bias may be even intended or at least willingly accepted, it constitutes a crucial problem in informal processes. When the aim is inclusive participation, the (self-)exclusion of specific actors or actor groups distorts the effectiveness of the process (Frantzeskaki/Rok 2018: 50).

The set-up of the co-creation process also depends on its ownership (Puerari/de Koning/von Wirth et al. 2018). While, as already mentioned, co-creation is based on the idea of participatory collaboration, there will always be one actor or a group of actors primarily responsible for the process (e.g., since they hold the cognitive and financial 
resources necessary for conducting the co-creative process or they have the power or control to initiate it). It is these specific actors that inevitably shape the design of the cocreative process. Of course, here power asymmetries come to the fore (Turnhout/Metze/Wyborn et al. 2020).

Co-creative participation brings about a specific configuration of the relationship between the initiator of the cocreative process - and thus the project 'owner' (mainly researchers and/or public authorities) - and the participants, mainly citizens or civil society actors. In co-creative processes, citizens and civil society actors take the stage as codesigners, co-implementers and co-initiators of problem solutions, while researchers rather adopt the role of enablers or facilitators. Transferred to the specific context of realworld laboratories, co-creation means that civil society actors and citizens are an active part of real-world experiments in their roles as designers, initiators and implementers. This understanding of co-creative participation emphasizes participation in processes of actual 'doing' and may come at the expense of neglecting participation in the decision-making that precedes, follows and is part of processes of actual experimentation.

Of course, one could argue that within a real-world laboratory a focus on open and fair participation in decisionmaking is neither necessary nor desirable in order to achieve sustainable transformations. However, the normative expectation here is that co-creation and real-world laboratories should also be about empowering citizens and civil society, which means that engagement with participatory decisionmaking is crucial for living up to this expectation (Beecroft/ Trenks/Rhodius et al. 2018). Questions of legitimacy then become crucial. In the literature on real-world laboratories, the degree of involvement of different actors and their decision-making capacities has already been discussed (MeyerSoylu/Parodi/Trenks et al. 2016). However, little attention has been paid to the crucial question of how decisions in the context of real-world laboratories can be made so that they are perceived as legitimate by stakeholders and affected people.

As already set out in Section 2, merely focusing on the participation of non-academic actors in the process of conducting real-world experiments without paying greater attention to fair and inclusive decision-making in real-world laboratories can eventually lead to a contestation of the legitimacy of the experimentation process and its outcomes. Legitimacy can thereby be regarded as a psychological property pertaining to an authority, institution or social arrangement, so that people perceive it as proper, appropriate and right in a normative sense (Tyler 2006: 375). Thus, legitimacy plays a major role in determining the acceptability of decisions and outcomes associated with such authorities, institutions and social arrangements. There are differ- ent motives for ascribing legitimacy as, for example, Weber (2019 [1921]: 115) has prominently elaborated. As empirical research has shown, a major source of legitimacy is the perceived fairness of decision-making processes (Tyler 2000). Since different worldviews, values and interests clash in real-world laboratories (Engels/Walz 2018), we require procedural mechanisms which acknowledge diversity and nevertheless leave room for negotiating common ground (Böschen 2021). Thus, in our view, in order to make participation in co-creative settings meaningful and effective, a more thorough and nuanced understanding of participation is necessary, particularly with a focus on the fairness of decision-making processes. Here, the concept deliberation, which is widely discussed as a means for ensuring the legitimacy of decisions among those who are affected by them (e.g., Manin 1987), can provide a fruitful basis for developing such a nuanced understanding. This can then inform the design of participation processes in real-world laboratories. We therefore briefly examine the existing literature on deliberation in the next section.

\section{Deliberative participation}

Deliberation is a participatory form of (democratic) opinion formation and decision-making concerning public matters. Since sustainability-oriented real-world laboratories, by definition, operate in real-world settings outside of science laboratories and are intended to advance the sustainability transformation of different fields of societal practice (e.g., mobility or food production and consumption), activities in real-world laboratories can be regarded as public matters. Furthermore, the conception of real-world laboratories as a transformative mode of research implicitly and explicitly draws on ideas of a democratization of research, as elaborated in earlier conceptions of transdisciplinary research (Funtowicz/Ravetz 1993; Gibbons/Limoges/Nowotny et al. 1994). Open dialogue among different kind of actors is thus an important form of participation in the context of realworld laboratories, because the idea of co-design and cocreation rests on the possibility of open and equal exchange among actors involved in and affected by the activities in the real-world laboratory (Parodi/Beecroft/Albiez et al. 2017).

However, as mentioned above, open dialogue does not unconditionally enhance the perceived legitimacy of realworld laboratory activities. There is a broad empirical as well as theoretical debate about the conditions under which participation is able to increase the (perceived) legitimacy of decisions. Here, some scholars propose participation in the mode of deliberation as a helpful approach (Bingham/ Nabatchi/O'Leary 2005; Curato/Sass/Ercan et al. 2020). To be sure, deliberation as such is not a form of participa- 
tion, but a mode of communication (Braun/Könninger 2018: 678). However, participation processes can nevertheless be conducted in a deliberative manner.

Deliberative decision-making entails decisions being made and problems solved in a dialogic, conversationbased manner (Habermas 1992: 332; Alcántara/Bach/Kuhn et al. 2016: 34). Deliberation can take place on many levels and in many sites (e.g., among political executives, experts or stakeholders, in citizen fora, via old and new media, in informal citizen gatherings) (Dryzek/Bächtiger/Chambers et al. 2019: 1146). In short, deliberation can be understood as a "debate and discussion aimed at producing reasonable, well-informed opinions in which participants are willing to revise preferences in light of discussion, new information, and claims made by fellow participants" (Chambers 2003: 309).

Jürgen Habermas, the originator of deliberative theory, states that norms, decisions and ideas gain legitimacy when all those potentially affected have the possibility to agree on their validity during deliberative discourse (Habermas 1992: 205-206). However, it is obvious that including all those potentially affected in a deliberative discourse becomes rather unrealistic with larger groups (Braun/ Könninger 2018: 678). Thus, deliberative discourses can only be fully inclusive under certain circumstances. Certain scholars have tried to identify different basic principles of a deliberative discourse, which can also be regarded as fundamental quality criteria of deliberation. These principles are (Steenbergen/Bächtiger/Spörndli et al. 2003; Bächtiger/ Niemeyer/Neblo et al. 2010; Alcántara/Bach/Kuhn et al. 2016; Bächtiger/Dryzek/Mansbridge et al. 2018) ${ }^{11}$ :

- Open participation and equality: everyone who wishes to participate in the discourse should be allowed to do so and should also have an equal opportunity to influence the discourse.

- Justification of arguments: the arguments put forward should be backed up by comprehensible and valid reasoning.

- Common good orientation: the discourse should serve the common good; if arguments are egocentric, it must be made clear how they also benefit the common good.

- Respect: mutual respect for the others' arguments.

- Aim at consensus: the ideal and desired outcome of deliberative processes is consensus, or at least agreeing to disagree and thus clarifying conflict lines.

\footnotetext{
${ }^{11}$ These criteria of deliberation can be traced back to Jürgen Habermas' concept of the "ideal speech situation" (Habermas 1973: 258).
}

- Sincerity: the arguments put forward should be presented truthfully and clearly so that they can be thoroughly scrutinized.

It is apparent that these criteria of deliberation sketch an ideal type of dialogic exchange, opinion formation and decision-making. Accordingly, many scholars have criticized the fact that they cannot be implemented empirically (Bächtiger/Niemeyer/Neblo et al. 2010: 37). The main criticisms refer primarily to the following two points (Baber/ Bartlett 2018: 758-762; Bächtiger/Dryzek/Mansbridge et al. 2018: 18-23): first, real-world deliberative processes are not as inclusive and fair as the theory claims; second, they run the risk of being undermined by elites who see deliberation as a technique of political co-optation. It thus follows that the empirical implementation of deliberative discourses always entails a certain "incompleteness" (Delli Carpini/Lomax Cook/Jacobs 2004: 317).

However, there are also means of mitigating the "incompleteness" of actual deliberative processes through specific participant selection methods. In order to avoid a bias towards well-educated, older, male, middle-class participants, both selective recruitment (e.g., in communities with lower income households) and random selection (to mirror the social stratification of the population) can be applied (Fung 2006: 67-68; Karpowitz/Raphael 2016: 16). Furthermore, power disparities between different social groups can be addressed by over-sampling participants who represent the least powerful groups and disadvantaged perspectives, as well as using specific moderation formats to help enhance inclusivity and fairness (for further details see: Karpowitz/ Raphael/Hammond 2009; Han/Schenck-Hamlin/SchenckHamlin 2015: 14-15). Thus, the deliberate inclusion of participants from all relevant groups can be regarded as a cornerstone for ensuring the perceived legitimacy of the results of deliberative processes (Pow/van Dijk/Marien 2020: 51).

Despite the fact that the ideal typical criteria for deliberation cannot be fully implemented in real-world deliberation processes (Bächtiger/Niemeyer/Neblo et al. 2010), empirical research nevertheless shows that deliberation processes can bring about beneficial and fruitful outcomes (Niemeyer 2013; Fung 2015; Dryzek/Bächtiger/Chambers et al. 2019). Since we cannot give a comprehensive overview of the state of empirical research on deliberation, we only briefly refer to three fields of empirical evidence that we consider of particular importance in the context of participation in realworld laboratories. First, certain formats of deliberation can significantly enhance participants' understanding of complex issues and also bring about changes in the preferences of the participants (Niemeyer 2013: 442). Thus, deliberation processes could foster an understanding of, and also 
support for, real-world laboratory activities among different social groups that are somehow affected by real-world experiments within their lifeworlds. As already mentioned in Section 2, such an understanding is an important precondition for the perceived legitimacy of real-world laboratory activities. Second, Fung (2015: 517-518) empirically illustrates how deliberation processes can improve the governance of wicked problems by contributing to a more inclusive and detailed problem framing, as well as by broadening the knowledge base for developing problem solutions. Fung refers to this as multisectoral problem solving. Thus, in order to design and conduct effective real-world experiments, it seems crucial to include all relevant knowledge stocks. It is not necessary to involve "everybody", which would go beyond the scope of a real-world laboratory project, but to ensure that all relevant perspectives are represented. Third, deliberation processes can help to avoid a polarization of interests and perspectives in the face of necessary decisions and thus have the potential to bring about socially robust decisions (Dryzek/Bächtiger/Chambers et al. 2019). Heterogeneous actors with different and sometimes also competing interests are involved in real-world laboratories (Engels/Walz 2018; McCrory/Schäpke/Holmén et al. 2020). These interests have to be integrated and conflicts have to be settled in order to be able to cooperate effectively. Here, deliberation as a mode of communication can help to overcome conflicts and build consensus in the face of heterogeneous interests.

In recent years, a "systemic turn" (Braun/Könninger 2018) has evolved in the field of deliberation theory, shifting attention from small-scale deliberation processes to deliberative participation systems as a whole. This systemic approach can refer to nations, but also to smaller social units such as schools, hospitals, associations or even realworld laboratories (Mansbridge/Bohman/Chambers et al. 2012: 2). From this perspective, the focus is on interrelations between different deliberative events and institutions, all of which fulfil different functions.

In terms of a deliberative system, Mansbridge, Bohman, Chambers et al. (2012: 11-12) differentiate between three central functions: first, an epistemic function (i.e., to produce well-informed preferences, opinions and decisions), second, an ethical function (i.e., to promote mutual respect) and, third, a democratic function (i.e., "the inclusion of multiple and plural voices, interests, concerns, and claims on the basis of feasible equality"; Mansbridge/Bohman/Chambers et al. 2012: 12). From a systemic perspective, individual deliberative events or institutions do not have to fulfil all of these functions at once. Some may fulfil epistemic functions, others democratic functions, and so on, but the crucial point is that, within a system, all the functions should be fulfilled in order to ensure the deliberative quality of the system. This means that the shortcomings of one deliberative event or institution can be balanced by the strengths of others. Thus, there is no need to strive for potentially unattainable perfection in every single case.

While the notion of a deliberative system discussed by Mansbridge, Bohman, Chambers et al. (2012) exclusively refers to a system of deliberative institutions and events, this idea can easily be transferred to a system consisting of different participatory institutions and events, be they deliberative or not. This opens up a systemic perspective on different forms of participation in real-world laboratories and stresses the importance of scrutinizing the interrelations between these forms of participation and their functions, since it is mainly these interrelations that make up the quality of participation in real-world laboratories.

As we have seen, deliberation as a mode of communication can be understood as a means of conflict resolution, opinion formation, consensus building and fair decisionmaking. It can complement and support co-creative forms of participation, which focus on the actual conduct of realworld experiments, in order to enhance the legitimacy of real-world laboratory activities. Understanding a real-world laboratory as a participation system consisting of different participatory events and participation formats opens up a perspective on the interplay and intersections of these events and formats that is crucial for the overall participatory quality of a real-world laboratory.

In the following section, we now elaborate and present our conceptual framework, which combines notions of both co-creative and deliberative participation.

\section{Co-creative experimentation and deliberative participation as two sides of the same coin}

As illustrated in Section 2, different approaches to participation were an integral part of the RNM. However, different kinds of shortcomings became apparent, both regarding the perceived legitimacy of some of the experimentation processes in the RNM and regarding the balancing and integration of the interests of the non-academic actors involved in decision-making processes. Reflecting on and addressing these shortcomings, we now try to sketch out an ideal-typical conceptual framework for participation in real-world laboratories. The framework is illustrated in Figure 2.

As already stated in Section 1, sustainability-oriented real-world laboratories aim to explore potential solutions for so-called wicked problems, which are, inter alia, characterized by ambiguity concerning problem definitions and consequently also concerning potential solutions. The term ambiguity describes "a situation of ambivalence in which 


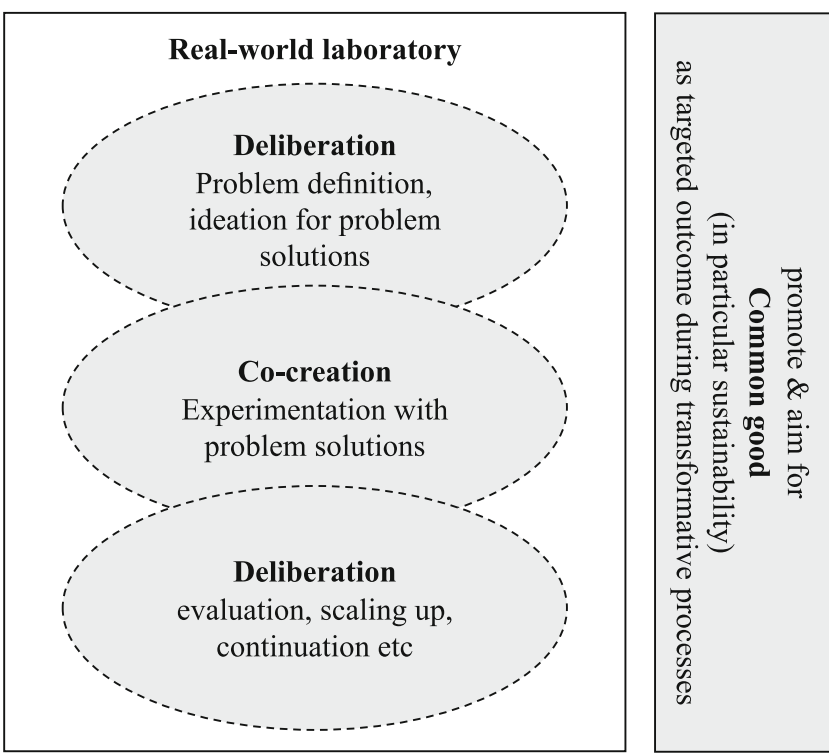

Figure 2 Integration of deliberation and co-creation in real-world laboratories

different and sometimes divergent streams of thinking and interpretation about the same risk phenomena and their circumstances are apparent" (Renn/Klinke 2013: 2039). Ambiguity mainly stems from differences in the values applied to normatively assess or interpret a certain phenomenon as desirable or undesirable. For example, driving bans as a potential solution to some of the negative socioecological side-effects of traffic in inner cities are regarded by some as highly desirable from a health or environmental point of view, while others regard them as an undesirable intervention in personal freedom.

Thereby, a deliberative approach, where competing values, arguments and beliefs are openly and inclusively discussed, can potentially resolve ambiguities. As Renn and Klinke (2013: 2051) put it: "The chance for resolving [these] conflicting expectations lies in the process of identifying overarching common values, and in defining options that allow a desirable lifestyle without compromising the vision of others". Thus, as long as no antagonistic conflicts over problem definitions exist, a deliberative approach to the definition of problems that should be tackled by realworld experiments in a real-world laboratory seems to be a suitable means of arriving at consensual and comprehensive problem definitions. All relevant stakeholders - be they representatives of civil society organizations, public officials or potentially affected citizens - should be heard in an open and fair dialogue (see also quality criteria of deliberation in Section 4) in order to effectively resolve ambiguities. This is crucial for securing the support of stakeholders for the real-world laboratory activities, since the exclusion or non-recognition of relevant actors and thus social perspectives seems likely to lead to a situation where the legitimacy of the experimentation processes is contested.

As illustrated in Section 4, deliberation does not imply that a consensus will or has to be reached. The outcome of a deliberative dialogue could also be a consensus about dissent. If it is not possible to arrive at a consensual problem definition in the context of a real-world laboratory, a next step could be to develop real-world experiments on the basis of different, or even competing, problem definitions. Furthermore, making the existence of different problem definitions transparent by means of a deliberative process can also be regarded as valuable in itself, since - as illustrated above - deliberation is supposed to enhance mutual understanding of diverging problem definitions by promoting social learning.

As soon as a consensus (about dissent) concerning problem definitions is established among relevant stakeholders, a phase of ideation can follow where ideas for potential solutions to the previously defined problems can be developed, discussed and refined. Here again, a deliberative approach to participation can be fruitful, in particular in the face of competing problem definitions. A deliberative approach in the phase of ideation can help to ensure that all relevant knowledge stocks are acknowledged and integrated in the process of problem solving and that, in the presence of competing problem definitions, each problem definition can be addressed by a specific solution.

After the initial phase of deliberation on problem definitions and potential solutions, a co-creative phase of participation can follow where the developed ideas are transferred into concrete plans and the actual experimentation takes place. The actual 'doing' is thereby given priority, and dialogic exchange can take a back seat. In the phase of experimentation, participation necessarily cannot be fully inclusive and open, since only actors representing and holding relevant knowledge stocks and resources (e.g., technical, legal, social, communicative competencies or local, experience-based, academic knowledge) are involved. Taking an emancipatory approach, marginalized actors can also be regarded as particularly relevant, in order to empower them to communicate their ideas and establish their own experimental projects which otherwise would not have been possible (Alcántara/Quint/Seebacher 2018: 139). For example, a citizen initiative with a novel idea for solving a certain everyday problem sustainably may be empowered within a real-world laboratory by providing them with support and resources. Of course, there is no ultimate and incontestable criterion for who should be considered relevant. Moreover, relevancies are already set by the respective scope of the problem definition(s) and the envisaged problem solutions. What is deemed relevant is thus also the outcome of the preceding 
deliberative participation process. However, taking a deliberative approach to participation allows these relevancies to be set in a fair and open way.

Due to the performative and spontaneous nature of realword experimentation, surprise is a constant companion in real-world laboratories (Gross 2019). This implies that what was deliberatively decided before the co-creative phase of experimentation cannot necessarily be implemented oneto-one in real-world experiments. Furthermore, the study of the unintended consequences of intentional experimentation is one of the key features of real-world laboratories. However, it therefore follows that as soon as the real-world experiments have been conducted and their - at least shortterm - effects have been observed, deliberative participation may again be worthwhile for resolving (or at least making visible) the ambiguities associated with the (unexpected) effects. In particular, when it comes to the scaling up and/or continuation of specific real-world experiments, ambiguities concerning the evaluation of the 'success' of specific real-world experiments become significant. While some consider the set-up of parklets, to take an example from the RNM, as a successful attempt to initiate a public debate about the right to public spaces that are being illegitimately restricted by parked cars, others perceive parklets as an unjustified intervention in their lifeworlds. Thus, the evaluation of the effects of such real-world experiments is not only a scientific endeavour that can be carried out in the realm of academia but also a public matter, since the real-world experiments take place in society. This can also provide a legitimatory basis for including the outcomes and results of spatially and temporally limited interventions in planning processes beyond the scope of a specific real-world laboratory (von Wirth/Levin-Keitel 2020: 104). Here again, the quality criteria for deliberative participation (see Section 4) can offer an appropriate yardstick for the design of respective dialogue-based participation processes for a fair and open discussion of the outcomes of real-world experiments among all the affected and concerned actors.

As long as real-world laboratories, as a tool of transformative research, are supposed to contribute to the sustainable transformation of society (however sustainability is actually supposed to be understood and operationalized), an idea of the common good is always implicitly present in real-world laboratories. In this regard, deliberative participation in general can be considered as a means to make implicit ideas of the common good explicit, and thus to ensure that experimentation in real-world laboratories does not lose sight of such ideas. Deliberative participation, both before and after the co-creative phase of experimentation, is relevant, since - as illustrated above - there are ambiguities associated with problem definitions, respective problem solutions and the evaluation of real-world experiments.
Additionally, using deliberative modes of participation in different stages of a real-world laboratory can provide a corrective to the influence of vested interests in the real-world laboratory. ${ }^{12}$

The potential and ideal-typical integration of deliberative and co-creative participation, as has been roughly sketched out and explicated in this section, is schematically illustrated in Figure 2.

As illustrated in Section 4, a systemic perspective on participation shifts the focus from the quality of single participatory events to the big picture of participation within a given social entity such as a real-world laboratory. Thus, the quality of participation in a real-world laboratory should not be judged on the basis of single participatory events. Here, the strengths of deliberative participation can make up for the weaknesses of co-creative participation, and vice versa. The distinction between talk-based deliberative participation on the one hand and co-creative participation which stresses actual doing in experimentation processes on the other hand is a purely analytical one. Deliberation and co-creation go hand in hand in practice. Thus, in practice, there are no distinct participation processes within a realworld laboratory which can be classified as solely deliberative or co-creative. Nevertheless, as elaborated above, the explicit consideration of deliberation and its preconditions can help to avoid conflicts over the legitimacy of experimentation processes and their outcomes, especially when certain actors feel ignored and relevant perspectives are not represented. Finally, a systemic perspective on participation in real-world laboratories also draws attention to the relation between participative experimentation in real-world laboratories and actual political decision-making. As long as there is no clearly structured connection between the experimentation in real-world laboratories and political decision-making bodies such as municipalities, and thus no retraceable and transparent impact on the actual governance of respective issues, participation in real-world laboratories will literally remain a mere laboratory exercise (Bogner 2012).

\section{Conclusions}

In this paper, we have proposed an ideal-typical conceptual framework (see Figure 2) that systematizes the combination of deliberative participation and co-creative experimentation, and offers a systemic perspective on participation in real-world laboratories. This framework is based on

\footnotetext{
12 The Discourse Quality Index (DQI) (Steenbergen/Bächtiger/ Spörndli et al. 2003: 27-30), for example, provides a systematic framework for assessing the quality of deliberative discussions.
} 
the learnings derived from practical experiences with participation processes in the RNM and can be regarded as a conceptual abstraction of these. However, the framework should be understood as an ideal-typical conceptualization of participation in real-world laboratories that is supposed to sensitize participants to the nuances and facets of different modes of participation and their systemic interplay. We do not claim to have developed a definite framework for participation in real-world laboratories, rather we hope to have delivered an initial basis for further and deeper discussions on the topic.

The crucial issue this paper deals with is that the virtues of the spontaneous, experimental and performative character of problem-solving in real-world laboratories go hand in hand with a partial neglect of the way decisions are made and (public) opinions are formed in this process, which can lead to legitimacy issues. As we have shown, considering and consulting the vast body of literature on deliberation helps us to gain a deeper understanding of the essential questions of who participates, under what circumstances, and producing which kind of outcomes. The answers to these questions are crucial for resolving and making visible ambiguities and thus creating meaningful outcomes that have a lasting impact from real-world laboratories. Without a thorough understanding of and reflexive approach to these questions, inclusive and fair participation remains unattainable, weakening the procedural legitimacy of experimentation in real-world laboratories. Thereby, participation that takes the core principles of deliberation seriously (open participation and equality, justification of arguments, commongood orientation, respect, consensus and sincerity; see Section 4) could be an effective complement to co-creative participation, moving beyond the mere idea that non-academic actors should be involved in every stage of a real-world laboratory. The elaboration of theoretically and empirically grounded quality criteria for participation is therefore an important step. It should be noted here that initial attempts to elaborate such criteria for 'good' participation in real-world laboratories have already been undertaken (see Eckart/Ley/ Häußler et al. 2018).

Since real-world laboratories are supposed to promote societal transformations towards sustainability, they can be regarded as public matters and are thus inevitably confronted with questions of legitimacy. Thereby, forms of deliberative participation could help to ensure that the outcomes of experimentation are perceived to be as legitimate as possible and thus socially robust. Currently, to our knowledge, this assumption has not been scrutinized empirically. This would be a relevant objective for future research on participation in sustainability-oriented real-world laboratories.

\section{References}

Alcántara, S.; Bach, N.; Kuhn, R.; Ullrich, P. (2016): Demokratietheorie und Partizipationspraxis. Analyse und Anwendungspotentiale deliberativer Verfahren. Wiesbaden. https://doi.org/10.1007/978-3-658-11221-9

Alcántara, S.; Quint, A.; Seebacher, A. (2018): Der Partizipationsmythos "Partizipation in Reallaboren muss repräsentativ sein”. In: Defila, R.; Di Giulio, A. (eds.): Transdisziplinär und transformativ forschen: Eine Methodensammlung. Wiesbaden, 137-141. https://doi.org/10. 1007/978-3-658-21530-9_7

Baber, W.; Bartlett, R. (2018): Deliberative Democracy and the Environment. In: Bächtiger, A.; Dryzek, J.S.; Mansbridge, J.J.; Warren, M.E. (eds.): The Oxford Handbook of Deliberative Democracy. An introduction. Oxford, 755-767. https://doi.org/10.1093/oxfordhb/ 9780198747369.013.59

Bächtiger, A.; Dryzek, J.S.; Mansbridge, J.J.; Warren, M.E. (2018): Deliberative Democracy: An Introduction. In: Bächtiger, A.; Dryzek, J.S.; Mansbridge, J.J.; Warren, M.E. (eds.): The Oxford Handbook of Deliberative Democracy. An introduction. Oxford, 1-34. https://doi. org/10.1093/oxfordhb/9780198747369.013.50

Bächtiger, A.; Niemeyer, S.; Neblo, M.; Steenbergen, M.R.; Steiner, J. (2010): Disentangling Diversity in Deliberative Democracy: Competing Theories, Their Blind Spots and Complementarities. In: The Journal of Political Philosophy 18, 1, 32-63. https://doi.org/10.1111/j.14679760.2009.00342.x

Beecroft, R.; Trenks, H.; Rhodius, R.; Benighaus, C.; Parodi, O. (2018): Reallabore als Rahmen transformativer und transdisziplinärer Forschung: Ziele und Designprinzipien. In: Defila, R.; Di Giulio, A. (eds.): Transdisziplinär und transformativ forschen. Eine Methodensammlung. Wiesbaden, 75-100. https://doi.org/10. 1007/978-3-658-21530-9_4

Bergmann, M.; Schäpke, N.; Marg, O.; Stelzer, F.; Lang, D.J.; Bossert, M.; Gantert, M.; Häußler, E.; Marquardt, E.; Piontek, F.M.; Potthast, T.; Rhodius, R.; Rudolph, M.; Ruddat, M.; Seebacher, A.; Sußmann, N. (2021): Transdisciplinary sustainability research in real-world labs: success factors and methods for change. In: Sustainability Science 16, 2, 541-564. https://doi.org/10. 1007/s11625-020-00886-8

Bingham, L.B.; Nabatchi, T.; O'Leary, R. (2005): The New Governance: Practices and Processes for Stakeholder and Citizen Participation in the Work of Government. In: Public Administration Review 65, 5, 547-558. https:// doi.org/10.1111/j.1540-6210.2005.00482.x

Böschen, S. (2021): Reallabore: Versammlungen unterschiedlicher Formen des Doing Sustainability verstehen 
- und gestalten. In: SONA - Netzwerk Soziologie der Nachhaltigkeit (ed.): Soziologie der Nachhaltigkeit. Bielefeld, 285-295. = Soziologie der Nachhaltigkeit 1. https://doi.org/10.14361/9783839451991

Bogner, A. (2012): The Paradox of Participation Experiments. In: Science, Technology and Human Values 37, 5, 506-527. https://doi.org/10.1177/0162243911430398

Braun, K.; Könninger, S. (2018): From experiments to ecosystems? Reviewing public participation, scientific governance and the systemic turn. In: Public Understanding of Science 27, 6, 674-689. https://doi.org/10.1177/ 0963662517717375

Brown, V.A.; Harris, J.A.; Russell, J.Y. (eds.) (2010): Tackling wicked problems. Through the transdisciplinary imagination. London.

Chambers, S. (2003): Deliberative Democratic Theory. In: Annual Review of Political Science 6, 1, 307-326. https://doi.org/10.1146/annurev.polisci.6.121901.085538

Curato, N.; Sass, J.; Ercan, S.A.; Niemeyer, S. (2020): Deliberative democracy in the age of serial crisis. In: International Political Science Review. https://doi.org/10. 1177/0192512120941882

Delli Carpini, M.X.; Lomax Cook, F.; Jacobs, L.R. (2004): Public deliberation, discursive participation, and citizen engagement: A review of empirical literature. In: Annual Review of Political Science 7, 315-344. https://doi.org/ 10.1146/annurev.polisci.7.121003.091630

Dryzek, J.S.; Bächtiger, A.; Chambers, S.; Cohent, J.; Druckman, J.N.; Felicetti, A.; Fishkin, J.S.; Farrell, D.M.; Fung, A.; Gutman, A.; Landemore, H.; Mansbridge, J.; Marien, S.; Neblo, M.A.; Niemeyer, S.; Setälä, M.; Slothuus, R.; Suiter, J.; Thompson, D.; Warren, M.E. (2019): The crisis of democracy and the science of deliberation: Citizens can avoid polarization and make sound decisions. In: Science 363, 6432, 1144-1146. https:// doi.org/10.1126/science.aaw2694

Eckart, J.; Ley, A.; Häußler, E.; Erl, T. (2018): Leitfragen für die Gestaltung von Partizipationsprozessen in Reallaboren. In: Defila, R.; Di Giulio, A. (eds.): Transdisziplinär und transformativ forschen: Eine Methodensammlung. Wiesbaden, 105-135. https://doi.org/10.1007/9783-658-21530-9_6

Engels, A.; Walz, K. (2018): Dealing with Multi-Perspectivity in Real-World Laboratories: Experiences from the Transdisciplinary Research Project Urban Transformation Laboratories. In: GAIA - Ecological Perspectives for Science and Society 27, S1, 39-45. https://doi.org/ 10.14512/gaia.27.S1.10

Frantzeskaki, N.; Kabisch, N. (2016): Designing a knowledge co-production operating space for urban environmental governance - Lessons from Rotterdam, Netherlands and Berlin, Germany. In: Environmental Science and Policy 62, 90-98. https://doi.org/10.1016/j.envsci. 2016.01.010

Frantzeskaki, N.; Rok, A. (2018): Co-producing urban sustainability transitions knowledge with community, policy and science. In: Environmental Innovation and Societal Transitions 29, 47-51. https://doi.org/10.1016/j.eist. 2018.08.001

Fung, A. (2006): Varieties of Participation in Complex Governance. In: Public Administration Review 66, 66-75.

Fung, A. (2015): Putting the Public Back into Governance: The Challenges of Citizen Participation and Its Future. In: Public Administration Review 75, 4, 513-522. https:// doi.org/10.1111/puar.12361

Funtowicz, S.O.; Ravetz, J.R. (1993): Science for the postnormal age. In: Futures 25, 7, 739-755. https://doi.org/ 10.1016/0016-3287(93)90022-L

Gibbons, M.; Limoges, C.; Nowotny, H.; Schwartzman, S.; Scott, P.; Trow, M. (1994): The new production of knowledge. The dynamics of science and research in contemporary societies. Los Angeles.

Grießhammer, R.; Brohmann, B. (2015): Wie Transformationen und gesellschaftliche Innovationen gelingen können. Dessau-Roßlau.

Gross, M. (2019): The Paradox of the Unexpected: Normal Surprises and Living with Nonknowledge. In: Environment: Science and Policy for Sustainable Development 61, 3, 20-25. https://doi.org/10.1080/00139157. 2019.1589308

Habermas, J. (1973): Wahrheitstheorien. In: Fahrenbach, H. (ed.): Wirklichkeit und Reflexion. Walter Schulz zum 60. Geburtstag. Pfullingen, 211-265.

Habermas, J. (1992): Faktizität und Geltung. Beiträge zur Diskurstheorie des Rechts und des demokratischen Rechtsstaats. Frankfurt am Main.

Han, S.; Schenck-Hamlin, W.; Schenck-Hamlin, D. (2015): Inclusion, Equality, and Discourse Quality in Citizen Deliberations on Broadband. In: Journal of Deliberative Democracy 11, 1, 3, 1-26. https://doi.org/10.16997/jdd. 220

Hölscher, K.; Wittmayer, J.M.; Loorbach, D. (2018): Transition versus transformation: What's the difference? In: Environmental Innovation and Societal Transitions 27, 1-3. https://doi.org/10.1016/j.eist.2017.10.007

Jahn, T.; Bergmann, M.; Keil, F. (2012): Transdisciplinarity. Between mainstreaming and marginalization. In: Ecological Economics 79, 1-10. https://doi.org/10.1016/j. ecolecon.2012.04.017

Karpowitz, C.F.; Raphael, C. (2016): Ideals of Inclusion in Deliberation. In: Journal of Public Deliberation 12, 2, 3, 1-23. https://doi.org/10.16997/jdd.255

Karpowitz, C.F.; Raphael, C.; Hammond, A.S. (2009): Deliberative democracy and inequality: Two cheers for en- 
clave deliberation among the disempowered. In: Politics and Society 37, 4, 576-615. https://doi.org/10.1177/ 0032329209349226

Kemmis, S.; McTaggart, R. (2005): Participatory action research. In: Denzin, N.K.; Lincoln, Y.S. (eds): The Sage handbook of qualitative research. Thousand Oaks, 559-604.

Kristof, K. (2017): Change Agents in gesellschaftlichen Veränderungsprozessen. In: Reinermann, J.-L.; Behr, F. (eds.): Die Experimentalstadt. Kreativität und die kulturelle Dimension der Nachhaltigen Entwicklung. Wiesbaden, 165-179. https://doi.org/10.1007/978-3658-14981-9_9

Lazarova, K.; Helfenstein, B.S.; Dietz, R.; Alcántara, S. (eds.) (2018): Parklets für Stuttgart: Ein Realexperiment. Stuttgart.

Löw, M. (2016): The sociology of space. Materiality, social structures, and action. New York.

Lund, D.H. (2018): Co-Creation in Urban Governance: From Inclusion to Innovation. In: Scandinavian Journal of Public Administration 22, 2, 3-17.

Manin, B. (1987): On Legitimacy and Political Deliberation. In: Political Theory 15, 3, 338-368.

Mansbridge, J.; Bohman, J.; Chambers, S.; Christiano, T.; Fung, A.; Parkinson, J.; Thompson, D.F.; Warren, M.E. (2012): A systemic approach to deliberative democracy. In: Parkinson, J.; Mansbridge, J. (eds.): Deliberative systems. Deliberative democracy at the large scale. Cambridge, 1-26.

Mauser, W.; Klepper, G.; Rice, M.; Schmalzbauer, B.S.; Hackmann, H.; Leemans, R.; Moore, H. (2013): Transdisciplinary global change research. The co-creation of knowledge for sustainability. In: Current Opinion in Environmental Sustainability 5, 3-4, 420-431. https://doi. org/10.1016/j.cosust.2013.07.001

McCrory, G.; Schäpke, N.; Holmén, J.; Holmberg, J. (2020): Sustainability-oriented labs in real-world contexts: An exploratory review. In: Journal of Cleaner Production 277, 3-4, 123202. https://doi.org/10.1016/j. jclepro.2020.123202

Meyer-Soylu, S.; Parodi, O.; Trenks, H.; Seebacher, A. (2016): Das Reallabor als Partizipationskontinuum. In: TATuP - Zeitschrift für Technikfolgenabschätzung in Theorie und Praxis 25, 3, 31-40. https://doi.org/10. 14512/tatup.25.3.31

Niemeyer, S. (2013): Democracy and Climate Change: What can Deliberative Democracy Contribute? In: Australian Journal of Politics and History 59, 3, 429-448. https://doi.org/10.1111/ajph.12025

Parodi, O.; Beecroft, R.; Albiez, M.; Quint, A.; Seebacher, A.; Tamm, K.; Waitz, C. (2017): The ABC of Real-world
Lab Methodology. From "Action Research" to "Participation" and Beyond. In: Trialog 126/127, 3-4, 74-82.

Pohl, C.; Truffer, B.; Hirsch Hadorn, G. (2017): Addressing Wicked Problems through Transdisciplinary Research. In: Frodeman, R.; Thompson Klein, J.; dos Santos Pacheco, R.C. (eds.): The Oxford Handbook of Interdisciplinarity. Oxford, 319-331.

Pow, J.; van Dijk, L.; Marien, S. (2020): It's Not Just the Taking Part that Counts: 'Like Me' Perceptions Connect the Wider Public to Minipublics. In: Journal of Deliberative Democracy 16, 2, 43-55. https://doi.org/10.16997/ jdd. 368

Puerari, E.; de Koning, J.; von Wirth, T.; Karré, P.; Mulder, I.; Loorbach, D. (2018): Co-Creation Dynamics in Urban Living Labs. In: Sustainability 10, 6, 1893. https://doi. org/10.3390/su10061893

Reallabor für nachhaltige Mobilitätskultur/Universität Stuttgart (eds.) (2018): Stuttgart in Bewegung. Berichte von unterwegs. Berlin.

Renn, O. (2008): Risk Governance: Coping with Uncertainty in a Complex World. London.

Renn, O.; Klinke, A. (2013): A Framework of Adaptive Risk Governance for Urban Planning. In: Sustainability 5, 5, 2036-2059. https://doi.org/10.3390/su5052036

Rittel, H.W.; Webber, M.M. (1973): Dilemmas in a General Theory of Planning. In: Policy Sciences 4, 2, 155-169. https://doi.org/10.1007/BF01405730

Rowe, G.; Frewer, L.J. (2000): Public Participation Methods: A Framework for Evaluation. In: Science, Technology and Human Values 25, 1, 3-29. https://doi.org/10. 1177/016224390002500101

Sanders, E. B.-N.; Stappers, P.J. (2008): Co-creation and the new landscapes of design. In: CoDesign 4, 1, 5-18. https://doi.org/10.1080/15710880701875068

Schäpke, N.; Bergmann, M.; Stelzer, F.; Lang, D.J. (2018): Labs in the Real World: Advancing Transdisciplinary Research and Sustainability Transformation: Mapping the Field and Emerging Lines of Inquiry. In: GAIA - Ecological Perspectives for Science and Society 27, S1, 8-11. https://doi.org/10.14512/gaia.27.S1.4

Schäpke, N.; Stelzer, F.; Caniglia, G.; Bergmann, M.; Wanner, M.; Singer-Brodowski, M.; Loorbach, D.; Olsson, P.; Baedeker, C.; Lang, D.J. (2018): Jointly Experimenting for Transformation? Shaping Real-World Laboratories by Comparing Them. In: GAIA - Ecological Perspectives for Science and Society 27, S1, 85-96. https://doi.org/ 10.14512/gaia.27.S1.16

Schneidewind, U.; Singer-Brodowski, M. (2013): Transformative Wissenschaft. Klimawandel im deutschen Wissenschafts- und Hochschulsystem. Marburg.

Schneidewind, U.; Augenstein, K.; Stelzer, F.; Wanner, M. (2018): Structure Matters: Real-World Laboratories as 
a New Type of Large-Scale Research Infrastructure: A Framework Inspired by Giddens' Structuration Theory. In: GAIA - Ecological Perspectives for Science and Society 27, S1, 12-17. https://doi.org/10.14512/gaia.27.S1. 5

Steenbergen, M.R.; Bächtiger, A.; Spörndli, M.; Steiner, J. (2003): Measuring Political Deliberation: A Discourse Quality Index. In: Comparative European Politics 1, 1, 21-48. https://doi.org/10.1057/palgrave.cep.6110002

Torfing, J.; Sørensen, E.; Røiseland, A. (2019): Transforming the Public Sector Into an Arena for Co-Creation: Barriers, Drivers, Benefits, and Ways Forward. In: Administration and Society 51, 5, 795-825. https://doi.org/ 10.1177/0095399716680057

Turnhout, E.; Metze, T.; Wyborn, C.; Klenk, N.; Louder, E. (2020): The politics of co-production: participation, power, and transformation. In: Current Opinion in Environmental Sustainability 42, 15-21. https://doi.org/10. 1016/j.cosust.2019.11.009

Tyler, T.R. (2000): Social Justice: Outcome and Procedure. In: International Journal of Psychology 35, 2, 117-125. https://doi.org/10.1080/002075900399411

Tyler, T.R. (2006): Psychological perspectives on legitimacy and legitimation. In: Annual Review of Psychology 57, 375-400. https://doi.org/10.1146/annurev.psych. 57.102904 .190038
Vetter, A.; Remer-Bollow, U. (2017): Bürger und Beteiligung in der Demokratie. Eine Einführung. Wiesbaden. https://doi.org/10.1007/978-3-658-13722-9

von Wirth, T.; Levin-Keitel, M. (2020): Lokale Nachhaltigkeitsexperimente als raumwirksame Interventionen: Theoretische Grundlagen und Handlungskonzepte. In: GAIA - Ecological Perspectives for Science and Society 29, 2, 98-105. https://doi.org/10.14512/gaia.29. 2.7

Voorberg, W.H.; Bekkers, V.J.J.M.; Tummers, L.G. (2015): A Systematic Review of Co-Creation and Co-Production: Embarking on the social innovation journey. In: Public Management Review 17, 9, 1333-1357. https://doi.org/ 10.1080/14719037.2014.930505

Wagner, F.; Miller, E. (2018): The Background and History of Real-World Laboratory Funding in Baden-Württemberg. In: GAIA - Ecological Perspectives for Science and Society 27, S1, 5 .

WBGU - Wissenschaftlicher Beirat der Bundesregierung Globale Umweltveränderungen (2016): Humanity on the move: Unlocking the transformative power of cities. Berlin.

Weber, M. (2019 [1921]): Economy and Society. A New Translation. Cambridge. 